\title{
ANÁLISES SOBRE A REFORMA SANITÁRIA E CONCEPÇÕES POLÍTICAS SUBJACENTES: A VISÃo AUTORITÁRIA DO IDEÁRIO PROGRESSISTA
}

Paulo Eduardo Elias *

\begin{abstract}
RESUMO: O propósito deste artigo é analisar as relações entre política, democracia e Reforma Sanitária no Brasil. A análise desenvolvida versa sobre um conjunto de textos inseridos na coletânea Reforma Sanitéria - om busca de uma teoria, dada sua significação e por representar a síntese do pensamento de importante vertente sobre este tema. Tomando o conjunto dos textos, o autor busca apreender as concepcões neles expressas acerca das relações Estado/Sociedade referidas ao projeto da Reforma Sanitária no Brasil, e a partir daf quais os caminhos possíveis para este projeto reformista.
\end{abstract}

O tema da Reforma Sanitária é introduzido em nosso meio no início dos anos 70 através dos Departamentos de Medicina Preventiva e/ou Social das escolas médicas, alcançando uma parcela dos profissionais de saúde e parte da sociedade brasileira, constituindo 0 que se convencionou denominar de movimento da Reforma Sanitária, de caráter nacional, e que impulsionará sua atuação no momento da transição do regime de ditadura militar para um governo civil. As motivações $e$ as leituras sobre as possibilidades deste movimento recobrem ampla gama de situações. Para alguns, o Movimento Sanitário, ao conquistar a hegemonia na luta pela Reforma Sanitária, imprimindo a direção do

- Docente do Departamento de Medicina Preventiva da Faculdade de Medicina da USP. Pesquisador do CEDEC. 
processo, "participaria da luta ideológica mais geral com o conjunto das forças sociais progressitas, da criação, portanto, dos pressupostos políticos, econômicos e ideológicos que tornariam possível o estabelecimento e a consolidação do socialismo em nosso País." (3 p. 189). Já outros autores advertem que o objetivo último da Reforma Sanitária é a constituição do Sistema Único de Saúde (2).

Há suposições razoáveis sobre a influência do processo de Reforma Sanitária ocorrido na Itália, a partir da segunda metade da década de 60 , e aquele que se deu no Brasil. Apesar dos pontos de congruência entre os dois processos - tais como a criação de um Serviço Sanitário Nacional público distintos procedimentos políticos-sociais embasam os dois processos, levando a diferenças marcantes entre ambos.

No caso italiano, a Reforma Sanitária funda-se nos pressupostos da representação social, através dos partidos políticos (principalmente o então $\mathrm{PCl}$ e o PSI, mas também a Democracia Cristã, o Partido Liberal Italiano e o Movimento Social Italiano, de orientação fascista) e entidades sindicais de distintas orientações políticas, atuando fortemente sobre o Estado e os governos, desenvolvendo-se as negociações no Parlamento, que em 1978 aprova proposta da maioria parlamentar e do governo que institui o Serviço Sanitário Nacional*.

No Brasil, o discurso da Reforma Sanitária é constituído a partir de uma pequena parcela da intelectualidade universitária da área da saúde, ganhando espaço na sociedade principalmente através do Centro Brasileiro de

\footnotetext{
* Para maiores informações sobre o tema ver Berlinguer, G.; Teixeira, S.F.; Campos, G.W. (1)
} 
Estudos em Saúde - CEBES *, atingindo assim parte dos profissionais -, aqueles mais afeitos à temática sanitária - e, posteriormente, representantes das Centrais Sindicais (quase exclusivamente profissionais de saúde) e alguns parlamentares (grande parte deles vinculados profissionalmente à saúde). Associam-se a estes setores, representantes dos Movimentos Populares de Saúde e algumas entidades associativas de profissionais de saúde e tem-se o denominado Movimento da Reforma Sanitária que terá grande atuação durante a VIII Conferência Nacional de Saúde realizado em 1986 e no período pré e pós Assembléia Nacional Constituinte. Segundo Teixeira(6), parte dos profissionais que se "filiavam" ao Movimento de Reforma Sanitária ocuparam postos importantes na estrutura do Ministério da Saúde e do INAMPS (Instituto Nacional de Assistência Médica da Previdência Social) intentando colocar em prática o ideário da Reforma Sanitária.

É relevante apontar que o processo italiano configura um padrão das democracias representativas clássicas, onde o movimento fundamental é da sociedade em direção ao Estado, enquanto a situação brasileira é bastante diversa desta, sendo o movimento fundamental do Estado em direção à sociedade. Mais adiante este tema será retomado.

Não obstante a distinção apontada nos dois processos na relação Estado/Sociedade, grande parte dos estudos existentes sobre a Reforma Sanitária brasileira, enfatiza os aspectos organizacionais das instituições de saúde, predominando o enfoque custo/benefício ou os aspectos da engenharia institucional dos principais serviços. Ao procederem desta maneira colocam pelo menos duas limitações à análise da problemática da Reforma Sanitária. A

- Entidade civil fundada em 1976, congregando profissionais vinculados ao sanitarismo, e responsável pela publicação Saúde em Debate, revista de divulgação de temas relativos à Reforma Sanitária. 
primeira delas é o excessivo privilegiamento da discussão nos marcos da dimensão técnica da saúde em detrimento dos aspectos políticos institucionais. A segunda, de certo modo decorrente da primeira, repõe a análise da Reforma Sanitária, por referência ao campo político institucional, em termos essencialmente "reformistas", isto é, na direção de responder estritamente às situações de crise do Estado na área de Saúde.

Autores como Faoro e Schwartzman dão elementos que permitem situar o risco de empobrecimento analítico deste tipo de procedimento, onde por um lado os problemas reais das instituições públicas - tais como o centralismo, a estrutura burocrática, o autoritarismo e principalmente a anti-democracia -, e por outro lado as questões referentes às Políticas Sociais, como suas relações com a construção da cidadania e seu papel universalizante e redistributivo, terminaram por ficarem desfocadas da análise.

Assinale-se também, na maioria da produção sobre este tema, a abordagem regida pela defesa de determinados princípios para e pelos setores populares, e as análises da Reforma Sanitária na perspectiva de suas positividades, realçando apenas os benefícios institucionais (e os há, como facilmente pode-se reconhecer pela leitura da Seção Saúde da Constituição Federal).

Ao discorrer sobre problemas da produção desenvolvida pela "inteligentsia reformista" * até meados dos anos 80 , Cohn aponta a ótica de resistência - durante o regime militar - e a busca da negociação política - nos estertores daquele regime e na conjuntura da transição democrática - como determinantes no balanço dessa produção, o predomínio da militância sobre a pesquisa e da denúncia sobre um conhecimento propositivo para a reconstrução do setor. $(2$ p.126) 
A produção mais recente, principalmente aquela realizada pelo Núcleo de Estudos Político-Sociais em Saúde da Escola Nacional de Saúde Pública, apoia-se no modelo marxista, a partir de categorias desenvolvidas por Antonio Gramsci, tais como hegemonia e guerra de posições. Para alguns autores filiados a esta perspectiva, "o uso desses conceitos tem por objetivo retirar a luta pela transformação da situação de saúde da população brasileira de um cotidiano específico para visualizá-la como parte - para eles privilegiada - da luta pela transformação da sociedade brasileira" (4 p. 181)

Os estudos acerca dos sentidos da Reforma Sanitária apresentam-se como um movimento pendular, recobrindo amplo espectro de situaçōes, tendo como limites a ênfase institucional e a transformação radical da sociedade através da revolução socialista. Cada uma das posições, polares e intermediárias, apresenta diferentes concepções sobre a Reforma Sanitária: alteração profunda no aparato institucional? Rupturas abruptas do modelo de atenção a Saúde? Movimento com ampla mobilização social e partidária?. Para esta mesma autora "a questão de fundo que perpassa todo o processo constitui, pois, a compreensão da relação Estado-sociedade na constituição e consolidação de uma ordem democrática" (2 p.128).

O propósito aqui presente é o de elaborar uma análise sobre a Reforma Sanitária Brasileira partindo de vários estudos já existentes $(1,2,9,13)$, e apontar problemas e colocar questões da ótica de uma leitura que busca evidenciar o pensamento político subjacente às análises sobre este tema.

Para tal, a análise proposta dialogará mais de perto com um conjunto de textos inseridos na coletânea Reforma Sanitária - em busca de uma teoria,

\footnotetext{
* Escorel, S.; op. cit. p. 181 .
} 
dada a sua significação e, de certa forma, por representar a síntese de importante vertente do pensamento sobre a Reforma Sanitária no Brasil. A análise a ser apresentada tem como guia e ponto de partida os textos de Cohn e de Oliveira em contraposição as concepções expressas na produção dominante sobre a reestruturação sanitária no Brasil.

Duas ordens de problemas podem ser apontados em relação à análise da Reforma Sanitária, presentes principalmente nos estudos de alguns autores que utilizam conceitos gramscianos.

Primeiro, a saúde é tratada como valor universal, indivisível e núcleo subversivo da estrutura social, e nestes termos passa a ser entendida como possibilidade de promover a transformação social através da construção de um bloco histórico ou, no mínimo, participar dela como um catalizador. Esta concepção tem como pressuposto básico a luta de classes combinada à impossibilidade de a classe dominante atender os interesses dos dominados em relação à saúde. $O$ inimigo visível desta postura são os denominados projetos neo-liberais, e o inimigo oculto, as propostas do Welfare State para o setor saúde.

Sobre o projeto liberal escreveu Wanderley Guilherme dos Santos(10) que o mesmo só se torna visível na medida em que exista um ator - a burguesia suficientemente forte para a competição política. Uma classe burguesa organizada com o objetivo de moldar o aparelho de Estado simultâneamente à estruturação da sociedade de acordo com a lógica do mercado (portanto, organizada como ator político) não existiu no Brasil até recentemente.

No caso do Welfare State típico, pressupõe-se, de um lado, uma sociedade civil organizada o suficiente para exercer um contrôle público do 
Estado, com movimento sindical forte e coeso, e de outro, uma situação de expansão econômica geradora de um excedente que permita ao Estado realizar políticas redistributivas. Quer nos parecer que a atual situação brasileira está muito longe disto. Assim pelo menos estes fantasmas devem ser abandonados em benefício de questões mais relevantes, tais como a consolidação da democracia e a constituição da cidadania(10 p. 110).

O segundo problema, de certa forma decorrente do anterior, é que a Reforma Sanitária passa como sendo a estratégia possível para a transformação social. Assim, é tomada como proposta unívoca e acabada, constituindo-se um fim em si mesma e realçadas apenas suas positividades. Nestes termos é enfocada como sujeito, e não como objeto a ser construído, analisado, inquirido e desvendado à procura de sua natureza e lógica política. Este modelo analítico apresenta vários inconvenientes, dentre os quais a facilidade de apontar, nos desacertos da realidade ou dos atores sociais, os "possíveis culpados" para o insucesso. Tome-se como exemplo a referência a uma passagem de dois autores que, ao analisarem os obstáculos à Reforma Sanitária no momento atual, vencido o que denominam neoliberalismo, apontam como problema a condução deste processo vir a ter a hegemonia dos social-democratas, disparando: "Neste caso poder-se-ia até chegar a uma sociedade modernizada e embasada na cidadania, mas certamente não teria atingido o homem, que continuaria condenado à préhistória da humanidade". (5 p. 116). Neste exemplo os social-democratas sentamse no banco dos réus. As questões a serem colocadas serão orientadas segundo dois eixos: as relações entre Estado e Sociedade e entre Democracia e Cidadania.

A partir da leitura dos textos sob este enfoque - e tomando os estudos da coletânea Reforma Sanitária - em busca de uma teoria como principal 
interlocutor -, apresenta-se como primeiro propósito identificar qual é o enfoque da relação Estado/Sociedade nos preceitos da Reforma Sanitária brasileira, e a partir daí quais os caminhos possíveis para esta Reforma.

Como segundo objetivo, dada uma concepção sobre a natureza da relação Estado/Sociedade, trata-se de tipificar a conformação da cidadania possível e, portanto, do grau de democracia que se pode depreender das análises sobre a Reforma Sanitária.

No decorrer dos textos, é curioso notar que os grandes ausentes são os Partidos Políticos. Trata-se de temas vários, relativos à democracia, representação de interesses, formulação de politicas e hegemonia, bloco histórico, burocracia e política de saúde, mas os Partidos Políticos só são citados para evidenciar suas debilidades, à exceção das referências ao processo italiano, em que são referidos diversos partidos de distintos matizes ideológicos.

No caso brasileiro, o interlocutor privilegiado do Movimento Sanitário é o Estado. É um discurso para e sobre o Estado. Ao discutir Burocracia e Política de Saúde diz Luchesi autor: "O fato do "Movimento Sanitário" (...) ter se dirigido à ocupação do aparelho de Estado, como estratégia preferencial (...) pode denotar a importância que o aparelho estatal tem na definição das políticas públicas no Brasil e a menor significação da clássica participação política" para arrematar, bem mais adiante, sobre o mesmo tema que " (...) a burocracia, enquanto aparato estatal, assume importância devido a própria importância do Estado (capitalista dependente), no processo de democratização/desenvolvimento da sociedade" (8 p. 174 e 179). 
Mais elaborada, esta concepção perpassa quase todos os artigos da citada coletânea, fornecendo algumas pistas em relação às questões de interesse mais imediato.

Primeiramente, no que se refere ao geral, passa a idéia de uma reforma social através de um Estado forte, não necessariamente autoritário. Este tipo de colocação é bastante cara aos pensadores políticos autoritários. Em relação ao Brasil, Oliveira Vianna apresenta uma visão cética no campo do desenvolvimento das instituições políticas. Sobre os partidos políticos escreveu ele: "... pela sua gênese ficaram sendo, assim, simples organizações de interesse privado com função no campo político" (15).

Também importa notar a concepção de Estado subjacente a este tipo de colocação. A idéia do Estado quase como sendo uma estrutura física, onde está localizado o Poder que deverá ser exercido em direção, ou melhor, sobre a sociedade. Aqui a aproximação maior dirige-se ao pensamento político que privilegia o Estado como ator, tal como ocorre nos estudos de Schwartzman e Faoro 4,11$)$. No caso deste último, esta abordagem é perfeitamente combinável com uma tradição marxista frente a uma certa autonomia do Estado.

O estudo de Faoro é voltado para a discussão desse caráter pesadamente estatal no Brasil. As análises centradas na idéia do Estado como ator ou como um locus neutro pronto a ser ocupado, de uma forma ou de outra desembocam numa concepção de centralização da política que fatalmente relega a um plano bastante secundário as clivagens regionais e aspectos relevantes na relação da instância regional com o poder central.

Ainda que em outra perspectiva analítica, é no clássico trabalho de Nunes Leal que vemos, magistralmente destacada, esta relação através da 
função eleitoral do "coronelismo". Diz o autor: "... ao tornar inteiramente eletivo o governo dos Estados, permitiu a montagem, nas antigas províncias, de sólidas máquinas eleitorais, essas máquinas eleitorais estáveis, que determinaram a instituição da "política dos governadores", repousavam justamente no compromisso "coronelista" (7 p. 253). Este tipo de abordagem favorece, e muito, uma leitura das características do Estado brasileiro, como por exemplo, sua vocação para incorporar o novo sem destruir o velho. É da rede de segurança do Estado voltada para os setores mais atrasados que nos dá conta a leitura do estudo de Schwartzman. Em relação à Reforma Sanitária, essa literatura traz elementos fundamentais para a compreensão dos eventos rotulados de "situação sui generis", como os citados na coletânea em discussão, a saber: "... - Movimento Sanitário em suas diferentes variantes acumulou êxitos, forçando reformas administrativas importantes, mas encontra dificuldades em levar à prática a descentralização e a unificação do Sistema de Saúde ..." (5 p. 92) .

Em síntese, para a maioria dos analistas que compõem a coletânea em questão, a concepção da relação entre Estado e Sociedade é fundada na ausência de representação, ou melhor dizendo, em certo tipo de representação que não se dá através dos Partidos Políticos, dado que para seus autores, "a desarticulação e despolitização da sociedade civil é também expressa através do clientelismo e fluidez dos partidos políticos atuantes na esfera pluralista" (14 p. 154 e 155).

Sobre as referências da autora acima citada, cabe retomar as contribuições de Campelo de Souza, que argumenta: " a fraqueza do sistema partidário é ela mesma sintoma da não institucionalização da participação política no Brasil". E mais adiante, ao criticar o tratamento usual dado ao clientelismo na literatura corrente, analisa que "faltando (à literatura corrente) um foco ao 
mesmo tempo estrutural e político, ela é levada a tratar o clientelismo como "sobrevivência tradicionalista", ao invés de procurar esclarecer as relações entre Estado e Sistema Partidário e, dentro desse quadro entender as funções objetivas (estruturais) do clientelismo" (12 p. 33,34).

Na coletânea em análise, se a representação não se dá através dos partidos políticos, quais são suas possibilidades?

Após uma rápida, e logo abandonada, passagem pelo corporativismo como forma de intermediação dos interesses entre sociedade civil e Estado(14 p.141), duas concepções básicas são destacadas. A primeira enuncia que "o projeto da Reforma Sanitária, ainda que tenha partido de intelectuais do setor, visa atender principalmente às necessidades das classes subalternas, ao mesmo tempo em que fere interesses das grandes empresas privadas e das multinacionais da área de saúde. Nesse sentido, a luta pela Reforma Sanitária se insere no quadro mais geral da luta de classes no país" (5 p.93).

A segunda tenta explicar "que a participação do Movimento Sanitário junto ao Estado vem se dando não através das organizações que dele fazem parte, mas individualmente, através das lideranças que se destacam enquanto porta vozes das propostas reformadoras, e vieram ocupar cargos no aparelho de Estado, mas cuja participação é ao mesmo tempo resultado do peso e articulação do movimento" (14 p.154).

Para os dois autores a representação de interesses das classes subalternas é imanente à Reforma Sanitária, e esta torna-se sujeito da luta de classes, ou seja, sujeito da disputa pelo poder político na sociedade. 
Nesta perspectiva, a Reforma Sanitária pode ser idealizada como ela própria constituindo um partido a liderar, em nome das classes subalternas, a busca do poder, ou melhor, a tomada do poder de Estado.

Já para a segunda autora, a representação de interesses dá-se por meios individuais, enquanto portadores de um saber técnico ainda que "vinculados" e "respaldados" pelo Movimento Sanitário (aspas nossas). Neste enfoque privilegiam-se os aspectos referentes à engenharia institucional, ou melhor, à mudança ou transformação "por dentro" do Estado.

Não obstante as diferenças entre essas duas vertentes, ambas têm como forte ponto de contato uma concepção extremamente autoritária da relação representante/representado, com ausência de mecanismos de controle social desta relação; ou seja, apontam na direção de dificultar o florescimento da democracia e da cidadania.

Em relação à democracia, caminham na direção de corroborar o agudo ceticismo de Buarque de Holanda quando afirma que "a democracia no Brasil foi sempre um mal entendido" chamando a atenção mais adiante para o fato de que "os movimentos aparentemente reformadores, no Brasil, partiram quase sempre de cima para baixo..." (6 p. 119).

Em relação a cidadania, esta depende em boa medida das possibilidades que se colocam à estruturação da sociedade para contrabalançar "um dos mitos mais caros ao pensamento autoritário: o mito de que a sociedade tem ou deve ter um centro único e poderoso de fixação"(12 p. 174).

Para esta mesma autora(12) "trata-se, tanto antes como agora, da organização da sociedade civil", forçada pelo desenvolvimento e pela crescente 
complexidade econômico-social, mas ao mesmo tempo dificultada pelo peso das instituições e tradições ideológicas autoritário-estatais"(p.171), tradições estas razoavelmente encampadas por um certo pensamento da Reforma Sanitária.

Dadas as concepções presentes nesta coletânea acerca da relação Estado/Sociedade e a visão tendencialmente instrumental que se tem da democracia, expressa por vários dos autores, não resta outro caminho às análises que não o de apontar as mudanças através da atuação do Estado em direção à sociedade.

Assim, não é de surpreender que boa parte das propostas da Reforma Sanitária nasça do Estado e que mesmo o Movimento Sanitário diagnosticando sua fragilidade decorrente "da incapaciedade de ampliar suas bases de apoio de forma a englobar os supostos principais interessados na mudança da política de saúde" $(13 \mathrm{p}$.206), persista o enfrentamento com fantasmas da área da saúde, tais como o denominado neo-liberalismo e a socialdemocracia, acreditando na força de sua plataforma como fator de legitimação social. Ao criticar o racionalismo exarcebado, que "ao erigir em regra suprema os conceitos assim arquitetados, separou-os irremediavelmente da vida e criou com eles um sistema lógico, homogêneo, a-histórico", Holanda aponta o erro de se chamar a atenção para "as plataformas, os programas, as instituiçōes, como únicas realidades dignas de respeito" " 6 p. 134).

A nosso ver, a batalha para levar adiante um dado projeto de Reforma Sanitária no Brasil coloca como ponto central a consolidação da democracia e da cidadania. 
E esta tarefa será quase impossível sem o concurso de um sistema representativo de tipo partidário e da rigorosa separação nas relações sociais entre o público e o privado.

\section{REFERÊNCIAS BIBLIOGRÁFICAS}

01. Berlinguer, G., Teixeira, S.F., Campos, G.W.: Reforma Sanitária - Brasil - Itália, Ed. Hucitec/CEBES, Såo Paulo, 1988.

02. Cohn, A.: "Caminhos da Reforma Sanitária". In: Lua Nova, n.19, nov. 1989. Revista do Centro de Estudos de Cultura Contemporanea, Såo Paulo.

03. Escorel, S.: Saúde: Uma Questão Nacional. In Reforma Sanitária - em busca de uma teoria. Teixeira, S.F. (org) - S. Paulo: Cortez/Abrasco, 1989.

04. Faoro, R.: Os Donos do Poder: formaçáo do patronato polltico brasileiro.Vol. 2 ,Porto Alegre, Globo, 1977.

05. Gallo, E.; Nascimento, P.C.: Hegemonia, bloco Histórico e Movimento Sanitário. In Teixeira, S.F (org): Reforma Sanitária - em busca de uma teoria - S.Paulo: Cortez/Abrasco, 1989.

06. Hollanda, S.B.: Ralzes do Brasil. 6a. ediçăo. Rio de Janeiro, Editora José Olímpio, 1971.

07. Leal, V.N.: Coronelismo, enxada e voto: o municipio e o regime representativo, no Brasil. 2a.ed., Săo Paulo, Alfa-Omega, 1975 ..

08. Luchesi, G.: Burocracia e Politica de Saúde: Arena ou Ator? In Teixeira, S.F. (org): Reforma Sanitária - em busca de uma teoria. S. Paulo: Cortez/Abrasco, 1989.

09. Oliveira, J.A.: Reformas e Reformismos: para uma teoria politica da Reforma Sanitária. In: Costa, N.R. (org.): Demandas Populares, Polliticas Püblicas e Sacide, Vol. I, Ed. Vozes, Rio de Janeiro, 1989;

10. Santos, W.G.: Ordem Burguesa e Liberalismo Polltico. Såo Paulo. Ed. Duas Cidades, 1978 ..

11. Schwartzman, S.: Bases do Autoritarismo Brasileiro. Rio de Janeiro: Campos, 1982. 
12. Souza, M.C.C.C. de: Estado e Partidos Politicos no Brasil (1930 a 1964). São Paulo, Alfa Omega, 1976 ..

13. Teixeira, S. F.; Mendonça, M. H.: Refomra Sanitária na Itália e no Brasil: Comparações. In Teixeira, S.F. (org). Reforma Sanitária - em busca de uma teoria. S. Paulo: Cortez/Abrasco, 1989.15. Vianna, F.J.O.: Instituiçóes Pollticas Brasileiras. Vol.II.(3a.ed.), Rio de Janeiro, Record, 1974 ..

14. Vaitsmam, J.: Corporativismo: Notas para sua aplicaçăo no campo da saúde. In Teixeira, S.F. (org): Refomra Sanitária - em busca de uma teoria. S. Paulo, Cortez/Abrasco, 1989.

15. Vianna, F.J.O. Instituiçóes politicas brasileiras, 3 ed. Rio de Janeiro, Record, 1974 v. 2. 